\title{
PENA DE MUERTE: ARGUMENTOS EN CONTRA
}

\author{
Jaime Náquira Riveros \\ Director del Departamento de Derecho Penal de la Facultad de Derecho de la \\ Pontificia Universidad Católica de Chile, Director del Programa de Post Grado en \\ Criminología de la Pontificia Universidad Católica de Chile y Profesor de Derecho \\ Penal en la Universidad Católica del Norte.
}

La verdad es que el tema sobre la pena de muerte es un tema que ha sido, es y será siempre discutido y discutible. Se dan argumentos en uno u otro sentido, pero creo que hoy en un aula de este tipo se ha podido escuchar una reflexión inteligente, seria, que lamentablemente no ha podido ser apreciada por lo que yo he podido percatarme, cuando este tema se trata en algunos medios de comunicación en tono festivo, porque no puede ser parte de un espectáculo, de un show, entremedio de canciones, de baile, con una copa o con un canapé en la mano. Creo que el tema de la pena de muerte es un tema muy serio, muy delicado, muy trascendente, y sólo se puede tocar en un ambiente como el que hay hoy en día, de lo contrario, es faltarle el respeto al tema, a las personas presentes y los eventuales afectados, de forma tal que concuerdo con quien hiciera uso anterior de la palabra, como ha planteado él, porque creo que de sus palabras se desprenden una cantidad enorme de argumentos del por qué no a la pena de muerte. No me cabe la menor duda después de escucharle, que él no es partidario de la pena de muerte, por lo cual yo me identifico.

Hago desde ya, y me ahorra una serie de palabras, el adherirme a toda esa reflexión que él formuló muy inteligentemente, y que yo comparto, y mi posición, en consecuencia, va a estar facilitada, porque me limitaré a decir otras cosas complementarias, o hacerme cargo de algunas reflexiones que se han hecho y que son desde mi personal punto de vista muy discutibles.

Desde ya, yo creo que el problema de la pena de muerte es un problema que se puede analizar desde distintas perspectivas, dimensiones, porque las tiene. En todo problema del ser humano es inevitable que distingamos una dimensión biológica, sicológica, social, político-criminal, criminológica, jurídico- penal, antropológica, religiosa, porque todas esas variables nos gusten o no están involucradas. En consecuencia, uno escucha muchos argumentos y se cruzan de repente, porque están mirados desde un punto de vista distinto, lo importante es clarificar la dimensión en la que estamos analizando el tema.

En consecuencia, por ejemplo, para mí la pena de muerte ¿qué sentido tiene?. Yo creo que la pena de muerte tiene un sentido induvitable, claro, inequívoco. Sin duda, que la pena de muerte permite canalizar, con el apoyo formal del Derecho, que en nuestro país la tiene, porque está consagrado, un sentimiento de odio, de resentimiento y de venganza. Es claro, si el ordenamiento jurídico penal contempla la 
pena de muerte, es una expectativa entre comillas, legal, no justa pero legal, que tiene el o a la familia afectada para poder pedir, reclamar, exigir una forma de compensar ese sentimiento de odio, resentimiento o de venganza, que puede ser, entendámonos, muy explicable, muy comprensible. Yo soy el primero en entender, el primero en comprender el sentimiento negativo de animadversión que puede experimentar la familia afectada, porque es humano que así sea, pero una cosa es que yo entienda, comprenda eso y una muy distinta es que yo justifique eso. Explicarme algo significa ver la causas, justificarlo es una cosa muy distinta, justificar un hecho supone contrastar el hecho con ciertos principios, con ciertos valores, y en esa contrastación, yo no estoy de acuerdo con la pena de muerte.

En consecuencia, es clarísimo que la pena de muerte tiene a favor el que le permite al afectado, o a quienes lo representan, o a sus familiares, el poder, pues, realizar ese sentimiento negativo. También se ha dicho que es una forma de deshacerse del delincuente, porque ha demostrado que no es útil a la sociedad, y que la sociedad en consecuencia no tiene la obligación de hacerse cargo de su futuro, porque implica, conlleva, un peligro inevitable para el resto de la sociedad en el futuro.

La verdad es que yo creo que aquí hay algo muy importante, yo digo que toda sanción penal debe respetar ciertas cosas fundamentales. Una de las ideas que ya se dijo es la dignidad del ser humano. Yo no creo que la dignidad del ser humano se pierda cuando éste ha protagonizado un hecho delictivo, por atroz que sea; ahora, si alguien me dice, no, yo creo que ontológicamente, jurídicamente, quien comete un hecho delictivo pierde la dignidad, bueno, yo nunca he visto esa reflexión, y creo que si no la he escuchado ni la he visto es, porque nadie se atreve a hacerla, y en ese sentido concuerdo plenamente con quien me antecedió en el uso de la palabra, que la sociedad debe siempre respetar la dignidad del ser humano, y una pena, cualquiera que ésta sea, no puede menoscabar, comprometer ese concepto que para mí hoy en día, en el campo del Derecho contemporáneo, en las declaraciones internacionales, es muy simple. Dignidad del ser humano.

En consecuencia, yo creo que todos estamos de acuerdo que la dignidad del ser humano es muy importante, si es así, imagino que una forma de respetar la dignidad del ser humano es respetarle su vida, porque de qué dignidad estamos hablando si le podemos quitar hasta la vida a ese portador o titular de dignidad. En consecuencia, si usamos la lógica, la dignidad implica la vida, y no se pierde la dignidad, porque alguien haya cometido un hecho delictivo por atroz que sea. Eso por un lado para mí es vital.

En segundo lugar creo que es muy importante el tener en cuenta como se dijo, cuál es el rol, papel, función u objetivo, cometido o finalidad o como queramos denominarle a la pena ¿qué esperamos de la pena?. Se dice en doctrina y digo en doctrina, porque una cosa es la doctrina y otra cosa es la práctica, que la pena implica una retribución, para algunos autores, hay quienes rechazan la retribución como finalidad de la pena, pero incluso para los que lo postulan, que en todo caso en este marco puede ser razonable, una retribución siempre debe respetar una cierta proporción frente al hecho que se ha cometido. Pues bien, yo creo que una pena mirado así implica una retribución, porque seamos francos, toda pena supone un castigo, supone un mal, supone un padecimiento, así que yo no puedo mediante expresiones disfrazar o maquillar esta realidad. Una pena supone un castigo, sin duda, en consecuencia hay algo retributivo y esa retribución se hace sobre la base de un hecho 
pasado, sin duda, yo castigo por algo que se hizo, no por algo que creo que se puede llegar a hacer, porque eso sería atroz, injusto, y sería más ilegal.

Pero parte de esa función, se habla que la pena tiene una función de prevención, una función disuasiva y aquí viene el problema, si bien la doctrina penal suele hablar de una prevención en general, bien sea intimidatoria, disuasiva o negativa, aversiva y bien, una prevención en general positiva ¿qué tan cierto es ésto si lo miramos en el terreno criminalógico? Dicho en otras palabras, ¿realmente cuando el legislador crea un delito y establece una sanción, realmente cuando el tribunal que conoce un hecho delictivo enjuicia al protagonista de éste y le aplica una sanción y ésta se ejecuta por las autoridades encargadas de ello ¿realmente el efecto de intimidación es real?.

La verdad de las cosas que desde un punto de vista criminalógico, y las investigaciones que sobre el particular se señalan, no en Chile por cierto, en Chile la investigación criminológica no ha existido nunca, pero en los países que se han dedicado a eso demuestra algo que es muy cierto y es lo siguiente: las personas que no están siempre predispuestas ni inclinadas a cometer hechos delictivos, pensemos los que estamos acá, el que existan tales o cuales delitos, el que tengan tal o cual pena ime frenan a mí para no cometer delitos? ¿Por qué yo no mato, no cometo delito de lesiones, no estafo, no cometo falsificación? ¿Por qué? ¿Yo no cometo esas conductas delictivas porque hay un Código Penal en el artículo tal o cual que sanciona con tal o cual pena?. La verdad de las cosas es que eso no es así, si yo no cometo esas conductas no lo hago, porque en mi formación, que comienza en la familia, muy importante, que continúa en el colegio con el grupo de amigos o a través de los medios de comunicación y las llamadas agencias de socialización, me han formado en ciertos principios y valores. En conclusión, pues a mí y a los que están aquí presentes, si no cometemos delitos no es porque exista un Código Penal, para nada, de forma tal que hay un segmento de la población en que el Código Penal exista o no exista, tenga o no tenga tal o cual pena, no pone ni quita, porque hay una formación detrás, en principio y valores que son los que nos frenan, eso es nuestra conciencia.

Pero tenemos otro sector de la población, aquellos que hacen de el delito su profesión, su actividad, su ocupación, su oficio y conversando con algunos de ellos, yo creo que los que hemos tenido esa oportunidad hemos llegado a igual conclusión ¿cuál es? muy simple, pues ellos nos dicen que la existencia del Poder Judicial, la existencia de la policía, la existencia en otras palabras de la autoridad, para ellos no constituyen, sino un riesgo social, riesgo como el que podemos tener nosotros cuando tomamos un vehículo de locomoción colectiva y que no podemos tener la certeza o la convicción absoluta que vamos a llegar a destino sin problemas, puede que choque y que, en consecuencia, salgamos lesionados o muertos, pues para el que hace del delito su actividad, la autoridad constituye un riesgo, e incluso muchos de ellos dicen, y esto es cierto, porque criminalógicamente es cierto, si considermos que en esta ciudad se cometen al mes 30 homicidios, 100 robos y 100 violaciones ¿qué porcentaje de estos delitos realmente suponen con posterioridad a su ejecución una pesquisa, supone un juicio, supone una condena? Y es claro que en toda esta cifra, la cifra negra u oculta es mucho mayor si la comparamos con las personas que han sido condenadas, con lo cual es cierto que estos ciudadanos que hacen del delito su profesión dicen. "Para mí es un riesgo, porque fíjese, yo me dedico a tal delito, tengo mi casa, tengo mi familia, los 
educo en buenos colegios, y claro, de repente me han pillado, pero oiga, si todo a nivel de resultado el haber y el debe me conviene, me compensa".

¿Adonde voy con esta reflexión? Que la famosa prevención, en general de carácter intimidatorio, a este grupo de ciudadanos no les va ni les viene, no les va ni les viene porque es para ellos un riesgo social ¿cómo para nosotros no nos va ni nos viene?. A mí me da lo mismo que mañana el legislador diga que tienen pena de muerte tales o cuales delitos, habría que considerarlo una estupidez. Pero en fin, yo seguiré actuando mi vida conforme a mis principios y a mis valores, de forma tal que tenemos un segmento de la población que no les va ni les viene y hay otro que tampoco le va y le viene, entonces alguien me va a decir a mí, bueno, y entonces esa llamada prevención de carácter intimidatorio ¿a quién afecta? Pues la verdad de las cosas que no lo sé, quiero pensar que quizás le afecta a personas de la tercera edad, a los abuelitos que son siempre a asustadizos y que, aunque son hombres buenos y probos, quizás a ellos los asuste. Desde allí que desde el punto de vista criminalógica la tal prevención en general de carácter intimidatorio, yo tengo mi gran duda, por lo que he señalado, que realmente exista.

Por otro lado se habla de una prevención especial que también se señaló momentos atrás, que consiste en orientar todo lo que significa la ejecución de la sanción penal para la reintegración, regeneración, resocialización o socialización, como queramos denominarla, del sujeto. Bueno, la pena de muerte lo impide. Ahora, obviamente que este trabajo de carácter de prevención especial siempre tiene que estar enmarcado una proporcionalidad, porque cierto, como se indicaba momentos atrás, quien ha hurtado o ha robado una gallina a lo mejor su estructura de personalidad nos llevaría un trabajo de 15 años, pero eso no parece razonable en proporción a lo que se ha hecho, lo disvalioso de ese hecho no es para lo otro, y es por eso que no se puede hacer, $y$ es por eso que no puede ser indeterminada, porque tiene que haber una proporción entre lo injusto, lo disvalioso, lo negativo del hecho con el mal, el castigo al que voy a someter al sujeto, trataré de que durante esa sanción que será, esperamos corta pueda realizarse un trabajo para reeducarlo y regenerarlo, pero nada más, y si no se puede, lamentable, pero ahí tiene que terminar.

En consecuencia, a la luz de la política criminal o a la luz de la criminología esto de la prevención es muy discutible, y hay un argumento que es de carácter históricocultural que es el siguiente y es muy sencillo. Se nos indicaba con razón que estos estudios criminológicos que a veces se señalan y que no se indican, porque en Chile no los hay, los hay fuera sí, se han hecho en Estados Unidos, en Inglaterra, en Alemania, en Francia, en los Países Bajos, en Canadá. En Inglaterra se ha puesto en algunas oportunidades la pena de muerte por un período determinado a ver que pasa, y la verdad es que las estadísticas que se han llevado a cabo observando estos periodos, los hay a favor y los hay en contra, es decir, en algunas oportunidades el bajar la penalidad, el cambiar la pena de muerte por una pena menor ha significado que la tasa de ese delito incremente, y en otras oportunidades, que incluso baje, cosa curiosa, no es que se conserve sino que baje. De forma tal que de un punto de vista de investigaciones criminalógicas no hay realmente una afirmación contundente, tajante y clara, pero si hay una de carácter histórico-cultural que para mí es clarísima ¿cuál es ésta? Todos sabemos que en las épocas pasadas, digamos que se yo, siglos pasados, y en las culturas incluso actuales, se prodigaba la pena de muerte con mucha generosidad. Pregunta ¿conocen Uds. algún país en el globo terráqueo o alguna cultura en donde se aplicó 
generosamente la pena de muerte, que nos pueda decir que como consecuencia de ese proceso histórico de aplicación de la pena de muerte desapareció el parricidio, el hurto, el robo, la violación, la estafa, los abusos deshonestos? No, en esas culturas que todavía existen que el que hurta le cortan la mano, el delito de hurto se sigue cometiendo, el robo igual ¿Qué indica eso? indica que el tal efecto disuasivo no funciona, no funciona, de forma tal que para mí es un argumento de gran, de carácter histórico-cultural muy importante, en ninguna cultura, en ninguna, ni en ningún país que se ha aplicado generosamente la pena de muerte puede decirme que el delito de parricidio desapareció, nunca más se cometió, que el homicidio tampoco, ninguno, eso para mí tiene un peso enorme, habla por sí solo, habla por la inutilidad en ese sentido, de la pena de muerte.

También se me puede indicar a mí que, incluso yo lo he escuchado desde una perspectiva religiosa, se ha dicho que incluso tiene una ventaja para el delincuente que es condenado a la pena de muerte, porque se le avisa con anticipación cuando se va a encontrar con el Señor, y entonces se puede preparar para encontrarse con El en buena forma. Yo lo he escuchado ese argumento. Yo les puedo de ese argumento decir lo siguiente, eso está muy bien para el creyente, pero acontece que en este mundo no sólo todos son creyentes, hay agnósticos también, hay quienes no son creyentes, entonces para este tipo de personas, porque todos son personas, cuando Ud. le aplica la pena de muerte lo mata entre comillas, definitivamente. Al que es creyente, si yo soy creyente y me van a ejecutar, yo me prepararé, espero, de la mejor forma posible, porque para mí es un tránsito hacia otra vida, pero el que no es creyente y Ud. le aplica la pena de muerte lo mata definitivamente, pregunta ¿Tiene la autoridad?. Se encuentra ante un agresor ilegítimo, no, nada, eso ya no existe, esa situación de, entre comillas, extrema necesidad en que se encontró el atacado, una situación de legítima defensa no la tiene la sociedad, no la tiene la sociedad. Yo he creído siempre que cuando se dicta la pena de muerte y se ejecuta la pena de muerte, en el fondo la autoridad lo que hace es repetir el hecho delictivo por el cual está ejecutando a ese condenado.

Creo que la sociedad y la autoridad cuando ejecuta una pena de muerte no da un buen ejemplo, al contrario, cae en lo mismo que el quiere reprimir. De forma tal que la sociedad repitiendo un hecho delictivo, repitiendo la ejecución, la destrucción de una vida, que a mi manera de ver es algo sagrado, bueno, no me parece a mí que sea razonable que la sociedad lo pueda hacer. De allí que no creo en que efectivamente se pueda decir que la sociedad cuando ejecuta la pena de muerte, pues de alguna forma lo hace por una legítima defensa, porque no está en situación de legítima defensa, puede tener otras alternativas, puede ser un presidio perpetuo y puede neutralizar, puede segregar, puede separar al sujeto peligroso por el tiempo que sea necesario, y en eso coincido plenamente con el que me antecedió, porque es efectivamente hoy en día en el Derecho Penal comparado, ya la pena de muerte está por la doctrina superada. En muchas legislaciones ya no se contempla, e incluso hay un movimiento muy fuerte en orden a que las cadenas perpetuas tampoco deben ser perpetuas, se consideran que son inhumanas, y hay topes hasta 20 años o hasta 30 años. La penas privativas de libertad no pueden exceder de esa cantidad, y en esa orientación va el Derecho Penal comparado, en consecuencia, pues, en nuestro país todavía está la pena de muerte, pues hay que reconocer que frente a la orientación que tiene el Derecho Penal comparado, pues, se aleja bastante. 
De forma tal que creo que pretender decir: "Mire, no va esta persona nunca más en los 10,20 ó 30 años ó 40 que le quedan de vida, nunca más va a poder recuperar su libertad", me parece que es un absurdo, porque ya indico, si la función de la pena una de ellas es la regeneración, la resocialización o como queramos denominarlo, y un sujeto después de un cierto lapso de tiempo 10, 15, o 20, por lo que se sea, nos demuestra que está rehabilitado, de hecho, hay una película muy hermosa protagonizada por Burt Lancaster, que siendo condenado a una prisión perpetua, pues él en definitiva se dedicó a estudiar los pájaros y terminó siendo un ornitólogo famoso y después recupera su libertad. Bueno yo le pregunto en ese caso, Ud. ¿le encuentra sentido que una persona que llega a destacarse en un ámbito, fruto de la reflexión que realiza en el interior de un penal y que realmente, realmente, nos evidencia que ya la sociedad no tiene por que tenerle temor? ¿tiene sentido dejarlo allí?. Para mí no, para mí no tiene sentido, por eso que tampoco yo soy partidario de decir: "Bueno, a Cupertino Andaur, como el caso en cuestión, pues que lo indulten pero que quede claro, escrito y registrado que bajo ningún concepto, ninguna autoridad podrá nunca permitirle salir en libertad", no lo sé. A lo mejor si no hace nada debe quedarse allí, perfecto, pero si hace algo distinto ¿por qué cerrarnos a que esa persona se reintegre? No le encuentro sentido, por lo menos la lógica me indica que no tiene sentido.

Ahora se señalaba también que un factor que lleva a la población a solicitar. requerir, anhelar la pena de muerte, es la inseguridad ciudadana. Es cierto, pero aquí hay que reconocer también el trabajo, bueno en el punto de vista de llegada, malo del mensaje que vende, a los medios de comunicación, si los medios de comunicación se dedican a explotar los delitos, porque hay un afán morboso y termina asustando a la gente y entonces la gente reacciona con miedo y el miedo al delito, y en fin, a todo eso y llevan a la autoridad, pues a solicitarle la mayor drasticidad en la penas y en la ejecución de la pena de muerte y todo lo demás, yo entiendo la reacción, me la explico más no la justifico.

Yo creo que aquí los medios de comunicación deberían tener realmente una autocensura y pensar muy bien lo que van a hacer, porque claro, si los medios de comunicación empiezan a explotar solamente las cosas tremendamente negativas, pues claro, cualquier persona que se encuentra en la radio, en la televisión, en la prensa con cosas absolutamente negativas y solamente todo estilando sangre, pues todos nos sentimos aterrorizados, pero eso es una trampa, es un mal para la sociedad. Yo creo que aquí los medios de comunicación tienen también un rol importante que jugar, es decir, presentar la realidad social tal como es, yo no digo que oculten lo negativo, no, pero no darle más importancia que la que tiene, de forma tal que en ese sentido, es cierto, puede despertarse una inseguridad ciudadana fruto de un mal manejo que pueden hacer los medios de comunicación.

Sin embargo, para mí en este sentido, por lo que ya les he indicado, yo creo que la pena de muerte no me parece, primero, porque atenta contra la dignidad del ser humano; segundo, porque del punto de vista criminológico y sobre la base de las funciones que se asignan a la pena, no cumple ninguna de éstas; tercero, porque me parece que la autoridad cuando ejecuta la pena de muerte en el fondo se limita a repetir el delito por el cual se supone que llevó al cadalso a ese sujeto, porque criminológicamente y histórico-culturalmente, la prueba más evidente que la pena de muerte que fue prodigada generosamente en otros tiempos jamás hizo desaparecer una tasa delictiva, y, en consecuencia, frente a todo eso, y que no hay tal legítima defensa, 
porque no existe la tal legítima defensa, pues me hace a mí pensar que la pena de muerte no tiene sentido, salvo claro está y en eso quiero ser muy franco, salvo claro está si alguien me dice: "No, es que es lo único que les permite al familiar o al afectado o a quienes se identifican con él, el poder calmar, ver realizado su anhelo de venganza, de resentimiento u odio", yo lo puedo entender, comprender, explicármelo, pero eso no lo puedo justificar, pero la sociedad no puede justificar, y quiero decir incluso más, esta idea que incluso yo la he escuchado de algún Magistrado en el sentido del argumento que va por la siguiente forma: "Quienes no son partidarios de la pena de muerte, habría que ver que pensarían si su hijo o su hija o su mujer, su cónyuge o que se yo, hubiera sido víctima de un atentado de este tipo, a ver si seguiría sosteniendo lo que sostiene". Yo creo que ese argumento a mí no me hace ninguna fuerza y voy a decir lo siguiente: Si yo fuera el padre de este chico que Cupertino Andaur lo mató en la forma que lo hizo, quizás, es muy probable que si yo me encuentro con el que lo hizo, en este caso con Cupertino Andaur, quizás yo me violente y termine matándolo, a lo mejor sí, a lo mejor no, no lo sé, pero no descarto esa posibilidad, pero eso es una cosa que todos Uds. comprenderían, se lo explicarían, pero lo que yo no entiendo, lo que yo no me explico y lo que yo no puedo aceptar, es que el tribunal o la autoridad judicial encargada de administrar Justicia pretenda administrar, entre comillas, justicia, es decir, con la objetividad necesaria, si se ponen los lentes del odio, de la venganza, y de los sentimientos. Eso lo podrán explicar Uds. respecto de mi reacción, pero que un Magistrado me diga a mí que él al administrar y al juzgar está poseído, porque se identifica con el sentimiento negativo de odio, de venganza y resentimiento, a mí se me eriza el cabello, porque significa que ese Magistrado no puede administrar justicia, de forma tal que eso no lo puede decir, no lo puede decir.

La Justicia se caracteriza, porque tiene que ser objetiva, prudente, serena y si no, les digo una cosa muy simple, todos nosotros cuando hemos tomado alguna resolución, una decisión fruto de la impulsividad ¿no terminamos el $90 \%$ de las veces arrepintiéndonos? Sin duda, porque la impulsividad, porque los sentimientos, porque la pasión, nunca es buena consejera, al contrario hay que hacerlo en forma serena, fría, de forma tal que ese argumento que por ahí se ha deslizado en los medios de comunicación de algún Magistrado diciendo que ese argumento, a mí no me pone ni me quita. Yo a lo mejor quizás me violento con Andaur si fuera el padre del niño, pero eso podrá ser explicado en mi contexto, pero que el juez que ve la causa, no, el juez de la causa no puede identificarse con un sentimiento de ese tipo, por el contrario, tiene que ser frío, sereno y objetivo, solamente eso. 